\title{
OSTEOBLAST AND GINGIVAL FIBROBLAST MARKERS IN DENTAL IMPLANT STUDIES
}

\author{
Veronika Pivodova $^{\text {a*}}$, Jana Frankova ${ }^{\mathrm{a}}$, Jitka Ulrichova ${ }^{\mathrm{a}, \mathrm{b}}$ \\ a Department of Medical Chemistry and Biochemistry, Faculty of Medicine and Dentistry, Palacky University Olomouc, \\ Czech Republic \\ ${ }^{b}$ Institute of Molecular and Translational Medicine, Faculty of Medicine and Dentistry, Palacky University Olomouc \\ E-mail:veronika.pivodova@gmail.com
}

Received: February 4, 2011; Accepted: March 3, 2011

Key words: Osteoblasts/Gingival fibroblasts/Extracellular matrix proteins/Dental implants

Background. Dental implants are a suitable option for the replacement of some or all missing teeth. Their main function is to secure the stability of the artificial tooth. The implant material interacts with several cell types including osteoblasts, gingival fibroblasts, periodontal ligament fibroblasts and monocytes. The most common material used is pure titanium which is corrosion resistant and has an elasticity modulus similar to that of bone. In recent years, diverse modified titanium surfaces have also been developed. The wound healing around the implant is a complex process that determines how well the host can heal and accept the implanted material. For this reason, search for markers of the biocompatibility of these new materials is paramount. To identify markers found to be suitable for studying the biocompatibility of dental implants.

Methods. Review of Pubmed and Web of Science databases for the years 1958-2010.

Conclusions. The surface of dental implant material should enhance firm attachment of the implant to junctional epithelium, soft connective tissue and bone. For the purposes of dental implant biocompatibility studies, a number of markers produced by osteoblasts or by cells of periodontal ligament have been proposed. In general, the most typical markers for osteoblasts and fibroblasts are alkaline phosphatase and collagen I, respectively. The involvement of both cell types in the inflammatory response is primarily evaluated by determination of tumour necrosis factor $\alpha$ and proinflammatory interleukins.

\section{INTRODUCTION}

Dental implants are a widely used alternative to some conventional dental treatments. However for a successful implant, biocompatibility and bioadhesiveness at the implant-tissue interface are crucial as the implant is in contact with soft tissue and bone. For this reason, the proteins expressed by the gingival fibroblasts and osteoblasts are important in the study of implant biocompatibility. Many of these proteins are secreted into the extracellular matrix (ECM). The durability of an implant depends on stable connection between implant surface and surrounding tissue ${ }^{1}$. It is known that the surface properties of implants impact the interaction with the biological system with bone formation being determined by four interrelated surface properties: composition, surface energy, topography and roughness ${ }^{2}$.

The most common dental implant material is titanium which is resistant to corrosion and has an elasticity modulus similar to that of bone. In recent years, diverse modified titanium surfaces have also been developed. Osseointegration is facilitated using hydroxyapatite coatings, higher surface roughness and surface-free energy. Increased surface roughness is achieved by blasting the surface with titanium oxide, analytical etching, sand blasting and acid etching ${ }^{3}$. One of the main aims of materials research for implantology is study and development of surface modification techniques to improve the bone integration of titanium-based dental implants ${ }^{46}$.

There are three types of dental implantations. The first, immediate implantation is based on placing the implant in the periodontium before the site of the missing tooth has healed. The second type is early implantation, which is 4-8 weeks after extraction of tooth. In the third type, the implant is inserted into healed bone. Hence, knowledge of the histology and structure of the periodontium and bone is relevant to study of the biocompability and bioadhesiveness of dental implants. The success of a material after implantation depends on the outcome of a number of complex processes. Initially the implantation induces an acute inflammatory response and this is followed by repair processes resulting in wound healing.

\section{THE PERIODONTIUM AND THE BONE}

\section{The periodontium}

The periodontium is the tissue which surrounds and supports the teeth. It consists of the periodontal ligament (PDL), the gingiva, the root cementum and the alveolar bone. The mature periodontal ligament includes periodontal ligament fibroblasts, neurovascular elements, epithelial cells, cementoblasts, osteoblasts and their precursors. The PDL also contains a large number of matrix 
macromolecules, such as collagens, glycosaminoglycans and various non-collagenous proteins ${ }^{7-9}$.

An important function of the root cementum is to invest and anchor the principal periodontal ligament fibres which spin like a meshwork between the root and alveolar bone, to the root. In addition, the cementum participates in the maintenance of occlusal adaptation, repair of root defects after resorption or fracture and, protection of the pulp ${ }^{10}$.

Periodontal tissue is mainly inhabited by gingival fibroblasts (GF) and periodontal ligament fibroblasts (PDLF)(ref. $\left.{ }^{11}\right)$. Gingival fibroblasts have an important role in the development, function and regeneration of the tooth-support structures ${ }^{12,13}$. They are also involved in the production and maintenance of the connective tissue matrix ${ }^{13,14}$. It is these cells that are responsible for the overall production and turnover of the extracellular matrix. Gingival fibroblasts maintain the synthesis and integrity of the gingival connective tissues. However, the fibroblasts have additional specialized functions as they are involved in the repair, remodeling and regeneration of the adjacent alveolar bone and cementum ${ }^{15}$.

\section{The bone}

Bone is a dense tissue, containing three types of cells, i.e. osteoblasts, osteocytes, and osteoclasts ${ }^{16}$. Osteoblasts are responsible for bone formation ${ }^{17}$ and osteocytes are the matured osteoblasts that have become entrapped in the deposited bone matrix. The function of osteoclasts is to break down the bone matrix ${ }^{16}$. Polarized mature osteoblasts secrete and deposit most bone matrix proteins. After implantation, osteoblasts adhere to the surface of the implant and mediate its strong fixture in a process called osseointegration. Osseointegration provides a direct structural and functional connection between ordered, living bone and the surface of a load carrying implant ${ }^{17}$. Therefore, in vitro studies with osteoblasts isolated from bone can offer insight into the biological performance of bone implant materials ${ }^{2}$.

\section{Cell models for in vitro studies}

The biocompatibility of dental implants can be studied using various cell models. Well-established primary cultures include human gingival fibroblasts, alveolar fibroblasts and human osteoblasts. Besides the primary cultures, in vitro studies often utilize cell lines such as human osteoblast-like cells SaOS-2 or human osteosarcoma cell line MG-63. In addition, more complex in vitro models consisting of two cell types are used. These co-cultures combine, for instance, certain types of bone cells, such as MG-63 cells or osteoprogenitor cells, with human umbilical vein endothelial cells or other types of endothelial cells ${ }^{18}$.

\section{MARKERS FOR DENTAL IMPLANT STUDIES}

Cell-matrix interactions depend on cytoskeletal organization, transmembrane integrin receptor expression and, most importantly, on the nature of the extracellular matrix. In bone and in periodontium, the extracellular matrix is composed of proteins such as collagen, fibronectin, laminin, osteopontin, osteonectin, alkaline phosphatase and other specific glycoproteins. The extracellular matrix is crucial in mediating cell adhesion to implanted materials since its organization and production modulates the degree of cell attachment to the materials. The success of non-biodegradable implants will depend primarily on biocompatibility, followed by the capacity of the surface topography of the implants to evince desired cell matrix, surface-cell matrix interactions ${ }^{19-21}$.

Proteins involved in the healing process

\section{Tenascin}

Tenascin is an extracellular matrix glycoprotein whose expression is regulated by growth factors such as TGF- $\beta$ (ref. $^{22,23}$ ) and by mechanical stress ${ }^{24,25}$. It is expressed during normal processes such as wound healing, nerve regeneration, tissue involution and in pathological states including vascular diseases and tumorogenesis ${ }^{26}$. In dental tissues, tenascin is involved in the differentiation of odontoblasts $^{27}$. These cells form the inside surface of the tooth and separate it from the cavum pulpae. Tenascin may thus also be associated with secondary dentine elaboration when pulp cells differentiate into odontoblasts in response to physical stimuli ${ }^{27-30}$.

\section{Fibronectin (FN)}

Fibronectins are heterodimeric adhesive glycoproteins (220 kDa) composed of two large subunits ${ }^{31}$. They are expressed by many cell types, epithelial, endothelial and mesenchymal ${ }^{32}$. The soluble form of fibronectin circulates in the blood and other body fluids. All the other forms assemble on the surface of cells and are deposited in the $\mathrm{ECM}$ as the highly insoluble $\mathrm{FN}^{33}$. Fibronectin has been implicated in a variety of cell functions, including adhesion, migration, growth and differentiation ${ }^{32,34}$. It is also found in association with dental basement membrane during tooth formation, polarization and differentiation of odontoblasts ${ }^{30,35}$. Fibronectin is considered to play important roles in the maintenance of normal tissue order and in interface interactions, since it mediates cell-matrix interactions, recognizing different cell types as well as bacteria $^{36,37}$ Fibronectin is also organized in focal adhesions which participate in cell locomotion and in cell adhesion $^{38-41}$

\section{Collagens}

The production of collagen is a key part of the formation of new connective tissue, a process critical to the durable performance of the implanted device. Periodontal ligament, gingival fibroblasts and osteoblasts produce collagens I and III ( ref. $^{26}$ ). Collagen I, one of the earliest osteoblast markers found, is upregulated in committed osteoprogenitors and its deposition as extracellular matrix appears to be a relatively early event in the osteoblast differentiation pathway ${ }^{39}$.Collagen I is one of the major components of gingival connective tissue. Collagen $\mathrm{I}$ is known to contribute to rapid regeneration of bone defects. 
Collagen III that constitutes $43 \%$ of total collagen ${ }^{42}$ may have an important function in the elasticity of the tissues $^{43}$, whereas collagen I is believed to maintain tissue architecture $^{44}$. Although collagens are the main organic components of dentine $80-90 \%$ (ref. $^{45}$ ), no collagen III is found in dentine $\mathrm{e}^{30,46,47}$.

\section{Osteonectin (ONEC) and osteopontin}

Osteonectin and osteopontin are adhesive glycoproteins specifically localized in the mineralized ECM of bone ${ }^{48,49}$ and synthesized primarily by osteoblasts, endothelial cells and megakaryocytes. Osteonectin and osteopontin are major noncollagenous proteins of bone $\mathrm{e}^{50}$. Both are responsible for the regulation of bone mineralization, since they promote the deposition of calcium phosphate ${ }^{30,51,52}$ and inhibit the growth of hydroxyapatite crystals $^{53-56}$.

\section{Alkaline phosphatase (ALP)}

Alkaline phosphatase, a glycoprotein belonging to a family of proteins anchored to the plasma membrane via glycosylphosphatidylinositol linkage ${ }^{57-59}$, catalyses the hydrolysis of phosphate esters in alkaline $\mathrm{pH}$. ALP is a common biochemical marker used to assess osteoblast differentiation and is considered to be involved in skeletal mineralization ${ }^{60,61}$. ALP is abundant in matrix vesicles which play a role in extracellular matrix processing and calcification of bone. The levels of ALP are increased just before mineralization is initiated. This aside, the precise role of ALP in mineralization remains unclear. It may be related to its calcium-binding action, generation of free phosphate, or degradation of mineralization inhibitors ${ }^{62}$. Increased levels of alkaline phosphatase activity have also been reported as one of the phenotypic changes of fibroblasts in wounds and inflammation ${ }^{59,63,64}$.

Receptor activator of nuclear factor- $\mathrm{B}$ (RANK), receptor activator of nuclear factor- $\kappa \mathrm{B}$ ligand (RANKL), parathyroid hormone $(\mathrm{PTH})$ receptor, osteoprotegerin

Receptor activator of nuclear factor $\kappa \mathrm{B}$ ligand (RANKL) is a member of the TNF receptor family and functions as a specific receptor for RANK. Osteoblasts express RANKL as a membrane-associated factor, while RANK is expressed by osteoclast progenitors and matured osteoclasts. Interaction of RANK with RANKL induces differentiation of pre-osteoclasts to osteoclasts ${ }^{65,66}$. In contrast, soluble RANK, also called osteoprotegerin (OPG), strongly inhibits osteoclast formation. The RANKL/OPG ratio is critical in the pathogenesis of bone diseases that result from increased bone resorption ${ }^{67}$. Expression of RANKL by osteoblasts arises during the action of osteotropic factors including parathyroid hormone (PTH), prostaglandin E2 and interleukin-11. It has been shown in various models that the PTH receptor increases bone mass when given intermittently but reduces bone mass when infused continuously. Consistently, PTH plays an important role in the regulation of osteoblast number and bone volume, presumably by decreasing osteoblast apoptosis $^{39,55,68}$.

\section{Laminin-5}

Laminin-5 plays an important structural role in the formation of hemidesmosomes, junction structures that serve to attach cells to underlying substrate. Hemidesmosomes ensure efficient attachment of epithelial cells to a variety of natural substances, including the enamel of the tooth and to implant material such as titanium and ceramics. In vitro, epithelial cells adhere more readily to laminin-5 than to other extracellular matrix elements, including laminin-1, laminin-2 and fibronectin, presumably due to enhanced hemidesmosome formation. Increased attachment, spreading and hemidesmosome formation of epithelial cells on laminin-5 passivated titanium indicate enhanced integration of tissue and metal and thus predict significant utility of this molecule for the long-term stabilization of implants ${ }^{69}$.

\section{Bone sialoprotein (BSP)}

Bone sialoprotein is one of the major calcium binding, non-collagenous glycosylated phosphoproteins in the extracellular matrix of mineralized tissues such as bone and dentine. BSP belongs to the small family of integrinbinding ligand $\mathrm{N}$-linked glycoproteins. It is expressed by several cell types associated with mineralized tissues but is produced in abundance by osteoblasts. The molecule of BSP is linear with little secondary structure. However, the protein is highly flexible, containing spatially segmented motifs that can bind several ECM constituents with diverse biological roles, including collagen, matrix metalloproteinases, hydroxyapatite, as well as integrins present in numerous cell types. In vitro experiments with bone derived osteoblasts and bone marrow cells have revealed that BSP not only stimulates calcification of newly synthesized organic matrix but also promotes cell proliferation and expression of osteoblastic phenotypes, suggesting that BSP may play a role in osteoblast differentiation and the onset of mineral formation ${ }^{70,71}$.

\section{Adhesion proteins}

Local stabilization of the implanted material requires strong adhesion of cells on the material surface. Cell adhesion to the extracellular matrix plays a fundamental role in regulation, cell differentiation, growth, and survival. Cell adhesion to both extracellular matrix and synthetic surfaces is dependent on integrin-mediated signal transduction and cytoskeletal proteins that form complexes known as focal adhesions. These complexes couple focal adhesion kinase (FAK), vinculin, integrins and actin filaments. Thus, focal contacts are sites of more or less stable connections between intra- and extracellular fibre systems $^{1,72,73}$

\section{Integrins}

Integrins are one of the major families of the cell adhesion receptors ${ }^{74}$. Each integrin is a heterodimer consisting of an independent $\alpha$ subunit and $\beta$ subunit $^{75}$ (see Fig. 1).

Both subunits are transmembrane proteins with their cytoplasmic domains attached to the cytoskeleton ${ }^{76}$. To date, $16 \alpha$ subunits and $9 \beta$ subunits are recognized. 
However, only specific combinations of $\alpha$ and $\beta$ subunits may form integrin heterodimers ${ }^{13,75}$.

Integrins interact with the ECM through their extracellular domains and with components of the cytoskeleton and various signaling molecules through their intracellular domains. Through these interactions, integrins can regulate many cellular functions such as cell adhesion, motility, shape, growth and differentiation ${ }^{16}$.

The expression of integrin in osteoblastic cells has been intensively studied. Osteoblasts have been shown to express a wide variety of integrins, including integrin subunits $\alpha_{1}, \alpha_{2}, \alpha_{3}, \alpha_{4}, \alpha_{5}, \alpha_{6}, \alpha v, \beta_{1}, \beta_{3}$, and $\beta_{5}\left(\right.$ ref. $\left.^{16}\right)$.

A characteristic feature of most integrin receptors is their ability to bind an array of ligands. Moreover, many extracellular matrix and cell surface adhesion proteins bind to multiple integrin receptors ${ }^{13,37,77-80}$.

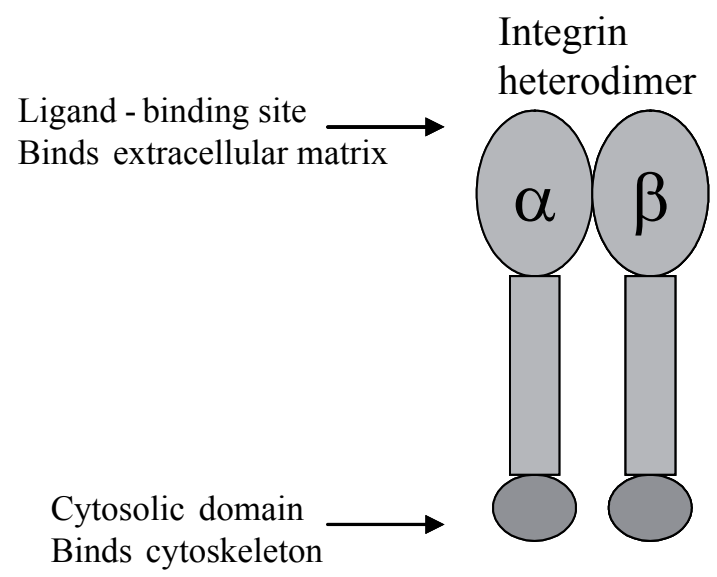

Fig. 1. The basic structure of the integrin.

\section{Vinculin}

Vinculin is a membrane-cytoskeletal protein. It forms a linkage between integrin adhesion molecules and actin cytoskeleton in focal adhesion plaques, and thus participates in regulation of both cell-cell and cell-extracellular matrix junctions. Vinculin contains a "head" domain, a "tail" and a proline-rich hinge region. The head domain binds to actin-binding proteins, talin and $\alpha$-actinin, whereas the tail domain binds to F-actin and paxillin (see Fig. 2). Moreover, intramolecular head-tail interactions may occur in the vinculin molecule. However, another molecule of vinculin enables the interactions between $\mathrm{N}$ - and $\mathrm{C}$-terminal domains, and the resulting conformational changes activate vinculin and allow it to bind to F-actin. The importance of vinculin for the structure and function of focal adhesions was confirmed by microinjection of the vinculin binding site. This targeted the vinculin within the cells, disrupted vinculin interactions with talin and a-actinin and thus disassembled focal adhesions ${ }^{81-84}$.

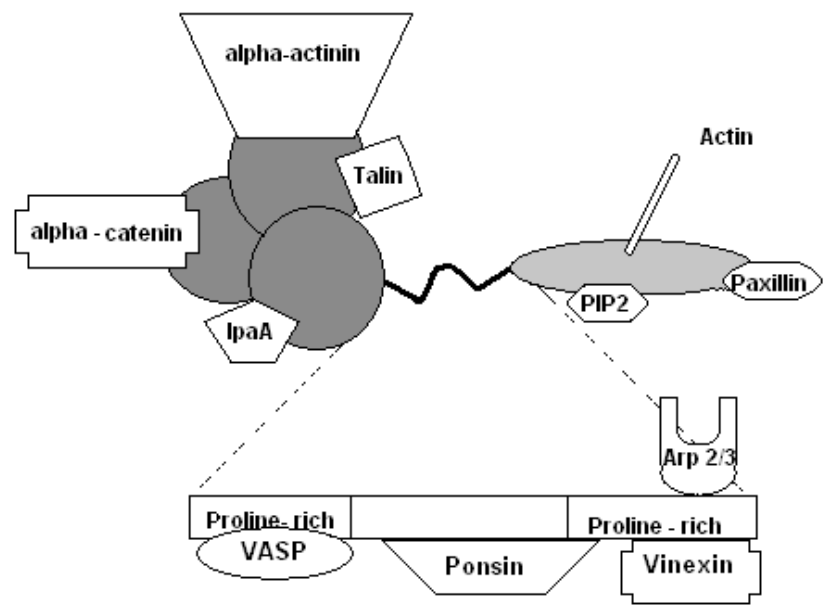

Fig. 2. The domain structure of vinculin and interacting partners (modified according to ref. ${ }^{85}$ ).

Proteins associated with the inflammatory response

Periodontal disease is a disorder of the oral connective tissues affecting the gingiva, periodontal ligament and alveolar bone. Gingivitis is characterized by inflammation of the gingival tissue around the teeth, while periodontitis includes loss of connective tissue, including the periodontal ligament and alveolar bone ${ }^{86}$. Inflammatory markers i.e. cytokines, matrix metalloproteinase and growth factors serve for determination of inflammation.

\section{Cytokines}

Cytokines are proteins secreted by various cells and mediate many cellular functions. Among others, they function as intercellular messengers essential for the pathogenesis of many diseases including peri-implantitis. In periodontology and implantology, cytokines are involved in inflammation-related alteration and repair of periodontal or peri-implant tissues ${ }^{87}$.

\section{Tumor necrosis factor-alpha (TNF- $\alpha$ )}

TNF- $\alpha$ is a potent osteoclastogenesis agent secreted by various cells, gingival fibroblasts and fibroblasts of the periodontal ligament ${ }^{88-90}$. It has been implicated in the bone loss and connective tissue destruction associated with periodontal disease ${ }^{88,91,92}$. This aside, TNF- $\alpha$ functions as a pro-inflammatory mediator stimulating production of matrix metalloproteinases (MMPs)(ref. ${ }^{93,94}$ ) and contributing to the development of such diseases as rheumatoid arthritis, periodontitis and multiple sclerosis ${ }^{95-99}$. TNF- $\alpha$ is also the main cytokine mediating response to gram-negative bacteria where the concentration of TNF- $\alpha$ reflects the amount of bacteria and stage of inflammation $^{87}$.

\section{Interleukins and chemokines}

IL-6 is produced by fibroblasts and its expression is increased at diseased periodontal sites including inflamed gingiva. IL- 6 stimulates bone resorption presumably by 
stimulating osteoclast formation. IL- 8 is produced by a variety of cells including monocytes, epithelial cells, endothelial cells as well as gingival fibroblasts in response to inflammatory mediators such as interleukin-1 $\beta$, and functions as a potent chemotactic factor for neutrophil granulocytes. Levels of IL-8 mRNA and protein have been found elevated in chronically inflamed gingival tissue as well as in gingival crevicular fluid from patients with periodontitis. Through the production of cytokines, such as IL-6 and IL-8, fibroblasts and epithelial cells act as accessory immune cells and contribute to periodontal destruction $^{86,87,100}$.

\section{Matrix metalloproteinases (MMPs)}

MMPs are produced by the cells of the connective tissue, e.g. fibroblasts, osteoblasts and odontoblasts synthesize and secrete MMPs into the ECM. In the ECM, MMPs are responsible for the degradation of extracellular matrix components during physiological processes such as morphogenesis, wound healing and cell migration ${ }^{101}$. The remodeling of ECM by MMPs generally occurs at neutral $\mathrm{pH}$. Under normal physiological conditions, the MMPs are expressed only when needed for tissue remodeling. In contrast, their aberrant expression is associated with the tissue destruction observed in many pathological conditions such as rheumatoid arthritis, periodontitis, cancer, tissue ulcers and fibrosis ${ }^{102}$.

MMPs are classified into five groups based on their structural homology and their substrate specificity (Table 1)(ref. ${ }^{102}$ ).

MMP-1, also called fibroblast or interstitial collagenase, is produced by several cells including fibroblasts, keratinocytes, chondrocytes, lymphocytes and monocytes. It preferentially degrades collagen molecules by enzymatic activity against triple helical collagen ${ }^{101}$. In general, collagens can be also degraded by other human interstitial collagenases such as MMP-8 and MMP-13 which release 3/4- to 1/4-length peptides. These peptides lose the triplehelical conformation and can be further degraded by the gelatinases MMP-2 and MMP-9(ref. $\left.{ }^{102}\right)$.

In periodontitis, the increased levels of MMP-1 detected in gingival tissue and in gingival fluid may be derived from fibroblasts and monocytes/macrophages. Gingival fibroblasts are in close contact with monocytes/ macrophages that are heavily distributed in the gingival tissue during periodontitis and these cell-to-cell contacts stimulate the expression of MMP-1( ref. $\left.^{101}\right)$. One particular MMP, matrilysin (PUMP-1, MMP-7), which is expressed during normal processes such as wound healing and bone differentiation, has been shown to degrade many ECM proteins including proteoglycans, fibronectin, laminin and others $^{103}$.
Table 1. Characteristics of all known MMPs (ref. ${ }^{102}$ ).

\begin{tabular}{|l|l|}
\hline MMP & Characteristics \\
\hline MMP-1, -8, -13,-18 & collagenases \\
\hline MMP-2, -9 & gelatinases \\
\hline MMP-3, -10,-11 & stromelysins \\
\hline MMP-14, -15, -16,-17,-24,-25 & transmembrane \\
\hline MMP-7, -26 & matrilysins \\
\hline
\end{tabular}

\section{Growth factors}

Regeneration of periodontal tissue is regulated by transforming growth factor- $\alpha(\mathrm{TGF}-\alpha)$ and transforming growth factor- $\beta$ (TGF- $\beta$ ). TGF- $\alpha$ regulates angiogenesis, while TGF- $\beta$ stimulates collagen I, fibronectin and osteonectin synthesis as well as bone matrix formation and basic fibroblast growth factor (bFGF). TGF- $\beta$ is known to be expressed during the implantation process and contributes to implant osseointegration ${ }^{104-108}$. TGF- $\beta$ has been also implicated in reparative dentinogenesis in the pulp ${ }^{109}$.

Epidermal growth factor (EGF) stimulates a variety of biological actions including proliferation and differentiation of epithelial and mesenchymal cells and plays a central role in inflammatory and immunological responses. In the periodontal tissues it is expressed by human periodontal ligament and gingival fibroblasts, junctional epithelial cells and alveolar bone cells. The expression of EGF might be different in periods of periodontal destruction quiescence and wound repair. EGF increases the expression of both MMP-1 and -3 in gingival fibroblasts ${ }^{100,110}$.

\section{CONCLUSION}

Dental implants are an ideal option for people in overall good oral health who have lost a tooth or teeth due to periodontal disease, injury or for some other reason. The success of dental implants, i.e. the ability to support a dental restoration, is critically dependent upon how much bone is available at the implant site ${ }^{111}$. The biocompatibility of the implant itself is determined by both the physical and chemical characteristics of the material and particular features of implant surface, such as the thickness of the oxide layer, microstructure and porosity. The surface of the dental implant material should enhance firm attachment of the implant to junction epithelium, soft connective tissue and bone $\mathrm{e}^{38,112}$. In summary, a number of markers produced by osteoblasts or by cells of periodontal ligament have been proposed for testing the dental implant biocompatibility, e.g. integrins, vinculin, alkaline phosphatase, collagen I and inflammatory cytokines. The most typical markers for osteoblasts and fibroblasts are alkaline phosphatase and collagen I, respectively. The involvement of both cell types in the inflammatory response is evaluated by determination of tumour necrosis factor $\alpha$ and proinflammatory interleukins. 


\section{ABBREVIATIONS}

ECM, Extracellular matrix; PDL, Periodontal ligament; PDLF, Periodontal ligament fibroblasts; MG-63, Human osteosarcoma cell line; FN, Fibronectin; Col, Collagen; ALP, Alkaline phosphatase; RANKL, Receptor activator of nuclear factor; PTH, Parathyroid hormone; OPG, Osteoprotegerin; BSP, Bone sialoprotein; IL, Interleukine; TNF- $\alpha$, Tumor necrosis factor alpha; MMPs, Metalloproteinases; TGF, Transforming growth factor; bFGF, Basic fibroblasts growth factor

\section{ACKNOWLEDGEMENT}

Supported by the grant No. MSM 6198959216, GACR 303/09/H048, LF_2010_022 and CZ.1.05/2.1.00/01.0030

\section{REFERENCES}

1. Eisenbarth E, Meyle J, Nachtigall W, Breme J. Influence of the surface structure of titanium materials on the adhesion of fibroblasts. Biomaterials 1996;17:1399-1403.

2. Jones FH. Teeth and bones: applications of surface science to dental materials and related biomaterials. Surface Science Reports 2001;42:79-205.

3. Pier-Francesco A, Adams RJ, Waters MGJ, Williams DW. Titanium surface modification and its effect on the adherence of Porphyromonas gingivalis: an in vitro study. Clinical Oral Implants Research 2006;17:633-637.

4. Cooper LF. A role for surface topography in creating and maintaining bone at titanium endosseous implants. Journal of Prosthetic Dentistry 2000;84:522-534.

5. Schwartz Z, Lohmann CH, Oefinger J, Bonewald LF, Dean DD, Boyan BD. Implant surface characteristics modulate differentiation behavior of cells in the osteoblastic lineage. Adv Dent res 1999;13:38-48.

6. De Angelis E, Ravanetti F, Cacchioli A, Corradi A, Giordano C, Candiani G, Chiesa R, Gabbi C, Borghetti P. Attachment, proliferation and osteogenic response of osteoblast-like cells cultured on titanium treated by a novel multiphase anodic spark deposition process. Journal of Biomedical Materials Research Part B-Applied Biomaterials 2008;88:280-289.

7. Gersdorff N, Miró X, Roediger M., Geffers R, Toepfer T, Huels A, Miosge N. Gene expression analysis of chronically inflamed and healthy human periodontal ligament cells in vivo. Dental Research Journal 2008;5:5-11.

8. Inoue M, LeGeros RZ, Hoffman C, Diamond K, Rosenberg PA, Craig RG. Effect of enamel matrix proteins on the phenotype expression of periodontal ligament cells cultured on dental materials. Journal of Biomedical Materials Research Part A 2004;69A:172179.

9. Ohno S, Ijiun C, Doi T, Yoneno K, Tanne K. Epression and activity of hyaluronidase in human periodontal ligament fibroblasts. Journal Periodontol 2002;73:1331-1337.

10. Bosshardt DD. Are cementoblasts a subpopulation of osteoblasts or a unique phenotype? Journal of Dental Research 2005;84:390-406.

11. Bruckmann C, Walboomers XF, Matsuzaka K, Jansen JA Periodontal ligament and gingival fibroblast adhesion to dentinlike textured surfaces. Biomaterials 2005;26:339-346.

12. Lekic P, Sodek J, McCulloch CA. Osteopontin and bone sialoprotein expression in regenerating rat periodontal ligament and alveolar bone. Anatomical Record 1996;244:50-8.

13. Palaiologou AA, Yukna RA, Moses R, Lallier TE. Gingival, dermal, and periodontal ligament fibroblasts express different extracellular matrix receptors. Journal of Periodontology 2001;72:798-807.
14. Biagini G, Checcini L, Pelliccioni GA, Solmi R. In vitro growth of periodontal fibroblasts on treated cementum. Quintessence Int 1992;23:335-340.

15. Park JC, Kim YB, Kim HJ, Jang HS, Kim HS, Kim BO, Han KY. Isolation and characterization of cultured human periodontal ligament fibroblast-specific cDNAs. Biochemical and Biophysical Research Communications 2001;282:1145-1153.

16. Siebers MC, ter Brugge PJ, Walboomers XF, Jansen JA. Integrins as linker proteins between osteoblasts and bone replacing materials. A critical review. Biomaterials 2005;26:137-146.

17. Steinemann SG. Titanium - the material of choice? Periodontol 2000 1998;17:7-21.

18. Unger RE, Sartoris A, Peters K, Motta A, Migliaresi C, Kunkel M, Bulnheim U, Rychly J, Kirkpatrick CJ. Tissue-like self-assembly in cocultures of endothelial cells and osteoblasts and the formation of microcapillary-like structures on three-dimensional porous biomaterials. Biomaterials 2007;28:3965-3976.

19. Berkovitz BKB. The Structure of the Periodontal-Ligament - an Update. European Journal of Orthodontics 1990;12:51-76.

20. Reichenberg E, Redlich M, Cancemi P, Zaks B, Pitaru S, Fontana S, Pucci-Minafra I, Palmon A. Proteomic analysis of protein components in periodontal ligament fibroblasts. Journal of Periodontology 2005;76:1645-1653.

21. Jayaraman M, Meyer U, Buhner M, Joos U, Wiesmann HP. Influence of titanium surfaces on attachment of osteoblast-like cells in vitro. Biomaterials 2004;25:625-631.

22. Erickson HP, Bourdon MA. Tenascin - an Extracellular-Matrix Protein Prominent in Specialized Embryonic-Tissues and Tumors. Annual Review of Cell Biology 1989;5:71-92.

23. Chiquet-Ehrismann R. What distinguishes tenascin from fibronectin? FASEB Journal 1990;4:2598-604.

24. Chiquet-Ehrismann R, Tannheimer M, Koch M, Bruner A, Spring J, Martin D, Baumgartner S, Chiquet M. Tenascin-C expression by fibroblastsis elevated in stressed collagen gels. Journal of Cell Biology 1994;127:1037-45.

25. Chiquet M. Mattisson M, Koch M., Tannheimer M., ChiquetEhrismann R. Regulation of extracellular matrix synthesis by mechanical stress. Biochemistry and Cell biology 1996;74:737-44.

26. Borsani E, Salgarello S, Mensi M, Boninsegna R, Stacchiotti A, Rezzani R, Sapelli P, Bianchi R, Rodella LF. Histochemical and immunohistochemical evaluation of gingival collagen and metalloproteinases in peri-implantitis. Acta Histochemica 2005;107:231240.

27. Thesleff I, Mackie E, Vainio S, Chiouetehrismann R. Changes in the Distribution of Tenascin during Tooth Development. Development 1987;101:289-296.

28. Lukinmaa PL, Mackie EJ, Thesleff I. Immunohistochemical Localization of the Matrix Glycoproteins - Tenascin and the EdSequence-Containing Form of Cellular Fibronectin - in Human Permanent Teeth and Periodontal-Ligament. Journal of Dental Research 1991;70:19-26.

29. Martinez EF, de Souza SOM, Correa L, de Araujo VC. Immunohistochemical localization of tenascin, fibronectin, and type III collagen in human dental pulp. Journal of Endodontics 2000;26:708-711.

30. Martinez EF, Araujo VC. In vitro immunoexpression of extracellular matrix proteins in dental pulpal and gingival human fibroblasts. International Endodontic Journal 2004;37:749-755.

31. Hynes RO. Fibronectins. Scientific American 1986;254:42-51.

32. Ruoslahti E. Fibronectin. Journal of Oral Pathology \& Medicine 1981;10:3-13.

33. Martinez-Hernandez A, Amenta PS. The basement membrane in pathology. Laboratory Investigation 1983;48:656-77.

34. Yamada KM, Olden K. Fibronectins - Adhesive Glycoproteins of Cell-Surface and Blood. Nature 1978;275:179-184.

35. Lesot H, Osman M, Ruch JV. Immunofluorescent Localization of Collagens, Fibronectin, and Laminin during Terminal Differentiation of Odontoblasts. Developmental Biology 1981;82:371-381.

36. Baum BJ, Wright WE. Demonstration of Fibronectin as a Major Extracellular Protein of Human Gingival Fibroblasts. Journal of Dental Research 1980;59:631-637. 
37. Moursi AM, Globus RK, Damsky CH. Interactions between integrin receptors and fibronectin are required for calvarial osteoblast differentiation in vitro. Journal of Cell Science 1997;110:2187-2196

38. Grill V, Sandrucci MA, Basa M, DiLenarda R, Dorigo E, Narducci P, Martelli AM, Delbello G, Bareggi R. The influence of dental metal alloys on cell proliferation and fibronectin arrangement in human fibroblast cultures. Archives of Oral Biology 1997;42:641647.

39. Aubin JE, Liu F, Malaval L, Gupta AK. Osteoblast and Chondroblast Differentiation. Bone 1995;17:S77-S83.

40. Moursi AM, Damsky CH, Lull J, Zimmerman D, Doty SB, Aota SI, Globus RK. Fibronectin regulates calvarial osteoblast differentiation. Journal of Cell Science 1996;109:1369-1380.

41. Francois P, Vaudaux P, Taborelli M, Tonetti M, Lew DP, Descouts P. Influence of surface treatments developed for oral implants on the physical and biological properties of titanium .2. Adsorption isotherms and biological activity of immobilized fibronectin. Clinical Oral Implants Research 1997;8:217-225.

42. Van Amerongen JP, Tonino GJ. The concentration, extractability and characterization of collagenin human dental pulp. Archives of oral biology 1983;28:339-45.

43. Shuttleworth CA, Berry L, Wilson N. Collagen-Synthesis in Rabbit Dental-Pulp Fibroblast-Cultures. Archives of oral biology 1980;25:201-205.

44. Narayanan AS, Page RC. Connective Tissues of the Periodontium - a Summary of Current Work. Collagen and Related Research 1983;3:33-64.

45. Linde A. Session II: cells and extracellular matrices of dental pulp. The extracellular matrix of the dental pulp and dentin. Journal of Dental Research 1985;64:523-29.

46. Scott PG, Veis A. Cyanogen-Bromide Peptides of Bovine Soluble and Insoluble Collagens .1. Characterization of Peptides from Soluble Type-I Collagen by Sodium Dodecylsulphate Polyacrylamide-Gel Electrophoresis. Connective Tissue Research 1976;4:107-116.

47. Morra M, Cassinelli C, Cascardo G, Cahalan P, Cahalan L, Fini M, Giardino R. Surface engineering of titanium by collagen immobilization. Surface characterization and in vitro and in vivo studies. Biomaterials 2003;24:4639-4654.

48. Wendel M, Sommarin Y, Heinegard D. Bone matrix proteins: Isolation and characterization of a novel cell-binding keratan sulfate proteoglycan (osteoadherin) from bovine bone. Journal of Cell Biology 1998;141:839-847.

49. Lallier TE, Spencer A, Fowler MM. Transcript profiling of periodontal fibroblasts and osteoblasts. Journal of Periodontology 2005;76:1044-1055.

50. Fisher LW, Termine JD. Noncollagenous Proteins Influencing the Local Mechanisms of Calcification. Clinical Orthopaedics and Related Research 1985:362-385.

51. Ingram RT, Clarke BL, Fisher LW, Fitzpatrick LA. Distribution of Noncollagenous Proteins in the Matrix of Adult Human Bone - Evidence of Anatomic and Functional-Heterogeneity. Journal of Bone and Mineral Research 1993;8:1019-1029.

52. Robey P. Vertebrate mineralized matrix proteins structure and function. Connective Tissue Research 1996;35:131-6.

53. Romberg RW, Werness PG, Riggs BL, Mann KG. Inhibition of Hydroxyapatite Crystal-Growth by Bone-Specific and Other Calcium-Binding Proteins. Biochemistry 1986;25:1176-1180.

54. Kelm RJ, Swords NA, Orfeo T, Mann KG. Osteonectin in Matrix Remodeling - a Plasminogen-Osteonectin-Collagen Complex. Journal of Biological Chemistry 1994;269:30147-30153.

55. Fassmann A, Izakovičová-Hollá L, Slapnička J. Kostní tkáňové inženýrství v orofaciální oblasti. Brno: Nucleus HK; 2006.

56. Termine JD, Kleinman HK, Whitson SW, Conn KM, Mcgarvey ML, Martin GR. Osteonectin, a Bone-Specific Protein Linking Mineral to Collagen. Cell 1981;26:99-105.

57. Noda M, Yoon K, Rodan GA, Koppel DE. High Lateral Mobility of Endogenous and Transfected Alkaline-Phosphatase - a Phosphatidylinositol-Anchored Membrane-Protein. Journal of Cell Biology 1987;105:1671-1677

58. Low MG. Glycosyl-Phosphatidylinositol - a Versatile Anchor for Cell-Surface Proteins. Faseb Journal 1989;3:1600-1608.
59. Abe T, Hara Y, Abe Y, Aida Y, Maeda K. Serum or growth factor deprivation induces the expression of alkaline phosphatase in human gingival fibroblasts. Journal of Dental Research 1998;77:17001707.

60. Harris H. The Human Alkaline-Phosphatases - What We Know and What We Dont Know. Clinica Chimica Acta 1990;186:133-150.

61. Leung KS, Fung KP, Sher AHL, Li CK, Lee KM. Plasma BoneSpecific Alkaline-Phosphatase as an Indicator of Osteoblastic Activity. Journal of Bone and Joint Surgery-British Volume 1993; 75:288-292.

62. Piattelli A, Scarano A, Corigliano M, Piattelli M. Effects of alkaline phosphatase on bone healing around plasma-sprayed titanium implants: A pilot study in rabbits. Biomaterials 1996;17:1443-1449.

63. Vorbrodt A. Histochemically Demonstrable Phosphatases and Protein Synthesis. Experimental Cell Research 1958;15:1-20.

64. Fullmer H, The histochemistry of the connective tissue. In: International review of connective tissue research, H. DA, Editor. 1965, Academic Press: New York.

65. Burgess TL, Qian YX, Kaufman S, Ring BD, Van G, Capparelli C, Kelley M, Hsu H, Boyle WJ, Dunstan CR, Hu S, Lacey DL. The ligand for osteoprotegerin (OPGL) directly activates mature osteoclasts. Journal of Cell Biology 1999;145:527-538.

66. Jimi E, Akiyama S, Tsurukai T, Okahashi N, Kobayashi K, Udagawa N, Nishihara T, Takahashi N, Suda T. Osteoclast differentiation factor acts as a multifunctional regulator in murine osteoclast differentiation and function. Journal of Immunology 1999;163:434-442.

67. Luvizuto ER, Queiroz TP, Dias SMD, Okamoto T, Dornelles RCM, Garcia IR, Okamoto R. Histomorphometric analysis and immunolocalization of RANKL and OPG during the alveolar healing process in female ovariectomized rats treated with oestrogen or raloxifene. Archives of Oral Biology 2010;55:52-59.

68. Jilka RL, Weinstein RS, Bellido T, Roberson P, Parfitt AM, Manolagas SC. Increased bone formation by prevention of osteoblast apoptosis with parathyroid hormone. Journal of Clinical Investigation 1999;104:439-446.

69. El-Ghannam A, Starr L, Jones J. Laminin-5 coating enhances epithelial cell attachment, spreading, and hemidesmosome assembly on Ti-6Al-4V implant material in vitro. Journal of Biomedical Materials Research 1998;41:30-40.

70. Gordon JAR, Tye CE, Sampaio AV, Underhill TM, Hunter GK, Goldberg HA. Bone sialoprotein expression enhances osteoblast differentiation and matrix mineralization in vitro. Bone 2007;41:462-473.

71. Xu L, Anderson AL, Lu QH, Wang JX. Role of fibrillar structure of collagenous carrier in bone sialoprotein-mediated matrix mineralization and osteoblast differentiation. Biomaterials 2007;28:750-761.

72. Goto T, Yoshinari M, Kobayashi S, Tanaka T. The initial attachment and subsequent behavior of osteoblastic cells and oral epithelial cells on titanium. Bio-Medical Materials and Engineering 2004; 14:537-544.

73. Diener A, Nebe B, Luthen F, Becker P, Beck U, Neumann HG, Rychly J. Control of focal adhesion dynamics by material surface characteristics. Biomaterials 2005;26:383-392.

74. Humphries JD, Byron A, Humphries MJ. Integrin ligands at a glance. Journal of Cell Science 2006;119:3901-3903.

75. Hynes RO. Integrins - Versatility, Modulation, and Signaling in Cell-Adhesion. Cell 1992;69:11-25.

76. Schoenwaelder SM, Burridge K. Bidirectional signaling between the cytoskeleton and integrins. Current Opinion in Cell Biology 1999;11:274-286.

77. Humphries MJ. The Molecular-Basis and Specificity of Integrin Ligand Interactions. Journal of Cell Science 1990;97:585-592.

78. Plow EF, Haas TK, Zhang L, Loftus J, Smith JW. Ligand binding to integrins. Journal of Biological Chemistry 2000;275:21785-21788.

79. Kramer PR, Janik-Keith A, Cai Z, Ma S, Watanabe I. Integrin mediated attachment of periodontal ligament to titanium surfaces. Dental Materials 2009;25:877-883.

80. Eslami A. The role of integrins in wound healing. The Science Creative Quarterly 2005 [http://www.scq.ubc.ca/the-role-of-integrins-in-wound-healing/]

81. Bois PRJ, O'Hara BP, Nietlispach D, Kirkpatrick J, Izard T. The vinculin binding sites of talin and alpha-actinin are sufficient to 
activate vinculin. Journal of Biological Chemistry 2006;281:72287236.

82. Takahashi H, Mitsushima M, Okada N, Ito T, Aizawa S, Akahane R, Umemoto T, Ueda K, Kioka N. Role of interaction with vinculin in recruitment of vinexins to focal adhesions. Biochemical and Biophysical Research Communications 2005;336:239-246.

83. Otto JJ. Vinculin. Cell Motility and the Cytoskeleton 1990;16:1-6.

84. Saunders RM, Holt MR, Jennings L, Sutton DH, Barsukov IL, Bobkov A, Liddington RC, Adamson EA, Dunn GA, Critchley DR. Role of vinculin in regulating focal adhesion turnover. European Journal of Cell Biology 2006:85:487-500.

85. Ziegler WH, Liddington RC, Critchley DR. The structure and regulation of vinculin. Trends in Cell Biology 2006;16:453-460.

86. Tipton DA, Lyle B, Babich H, Dabbous MK. In vitro cytotoxic and anti-inflammatory effects of myrrh oil on human gingival fibroblasts and epithelial cells. Toxicology in Vitro 2003;17:301-310.

87. Petković AB, Matić SM, Stamatović NV, Vojvodić DV, Todorović TM, Lazić ZR, Kozomara RJ. Proinflammatory cytokines (1L$1 \beta$ and TNF- $\alpha$ ) and chemokines (1L-8 and MIP- $1 \alpha$ ) as markers of peri-implant tissue condition. International journal of oral and maxillofacial surgery 2010;10.

88. Roberts FA, McCaffery KA, Michalek SM. Profile of cytokine mRNA expression in chronic adult periodontitis. Journal of Dental Research 1997;76:1833-1839.

89. Agarwal S, Chandra CS, Piesco NP, Langkamp HH, Bowen L, Baran C. Regulation of periodontal ligament cell functions by interleukin-1 beta. Infection and Immunity 1998;66:932-937.

90. Imatani T, Kato T, Okuda K. Production of inflammatory cytokines by human gingival fibroblasts stimulated by cell-surface preparations of Porphyromonas gingivalis. Oral Microbiology and Immunology 2001;16:65-72.

91. Quintero JC, Langkamp HH, Johns LP, Piesco NP, Agarwal S. Tumor-Necrosis-Factor-Alpha Regulates Expression of Lps Receptors on Periodontal-Ligament Cells. Journal of Dental Research 1995; 74:540-540.

92. Graves DT, Cochran D. The contribution of interleukin-1 and tumor necrosis factor to periodontal tissue destruction. Journal of Periodontology 2003;74:391-401.

93. Nishikawa M, Yamaguchi Y, Yoshitake K, Saeki Y. Effects of TNF alpha and prostaglandin E-2 on the expression of MMPs in human periodontal ligament fibroblasts. Journal of Periodontal Research 2002;37:167-176

94. Yongchaitrakul T, Lertsirirangson K, Pavasant P. Human periodontal ligament cells secrete macrophage colony-stimulating factor in response to tumor necrosis factor-alpha in vitro. Journal of Periodontology 2006;77:955-962.

95. Graves DT. The potential role of chemokines and inflammatory cytokines in periodontal disease progression. Clinical Infectious Diseases 1999;28:482-90.

96. Feldmann M, Brennan FM, Elliott MJ, Williams RO, Maini RN TNF alpha is an effective therapeutic target for rheumatoid arthritis. Ann N Y Acad Sci 1995;766:272-8.

97. Raine CS. Multiple-Sclerosis - Tnf Revisited, with Promise. Nature Medicine 1995;1:211-214.

98. Rapala K. The effect of tumor necrosis factor-alpha on wound healing - An experimental study. Annales Chirurgiae Et Gynaecologiae 1996;85:9.
99. Takemura A, Nakagawa I, Kawai S, Inaba H, Kato T, Hamada S, Amano A. Inhibitory effects of tumor necrosis factor-alpha on migration of human periodontal ligament cells. Journal of Periodontology 2006;77:883-890.

100. Yucel-Lindberg T, Brunius G. Epidermal growth factor synergistically enhances interleukin-8 production in human gingival fibroblasts stimulated with interleukin-1 beta. Archives of Oral Biology 2006;51:892-898.

101. Domeij H, Modeer T, Quezada HC, Yucel-Lindberg T. Cell expression of MMP-1 and TIMP-1 in co-cultures of human gingival fibroblasts and monocytes: The involvement of ICAM1. Biochemical and Biophysical Research Communications 2005;338:1825-1833.

102. Chaussain-Miller C, Fioretti F, Goldberg M, Menashi S. The role of matrix metalloproteinases (MMPs) in human caries. Journal of Dental Research 2006;85:22-32.

103. Bair EL, Massey CP, Tran NL, Borchers AH, Heimark RL, Cress AE, Bowden GT. Integrin- and cadherin-mediated induction of the matrix metalloprotease matrilysin in clocultures of malignant oral squamous cell carcinoma cells and dermal fibroblasts. Experimental Cell Research 2001;270:259-267.

104. Schierano G, Bassi F, Gassino G, Mareschi K, Bellone G, Preti G. Cytokine production and bone remodeling in patients wearing overdentures on oral implants. Journal of Dental Research 2000;79:1675-1682.

105. Schierano G, Bellone G, Manzella C, Preti G, Emanuelli G. In vitro effect of transforming growth factor-beta on adhesion molecule expression by human gingival fibroblasts cultured in the presence of a titanium abutment. Journal of Periodontology 2001;72:16581665.

106. Crawford JM. Distribution of ICAM-1, LFA-3 and HLA-DR in Healthy and Diseased Gingival Tissues. Journal of Periodontal Research 1992;27:291-298.

107. Crawford JM, Hopp B. Junctional Epithelium Expresses the Intercellular-Adhesion Molecule Icam-1. Journal of Periodontal Research 1990;25:254-256.

108. Stepanova II. The use of fibroblasts in periodontology and implantology. Bulletin of Experimental Biology and Medicine 2007; 144:147-150.

109. Derringer KA, Linden RWA. Vascular endothelial growth factor, fibroblast growth factor 2, platelet derived growth factor and transforming growth factor beta released in human dental pulp following orthodontic force. Archives of oral biology 2004;49:631641.

110. Cury PR, de Araujo VC, Canauez F, Furuse C, Leite KRM, de Araujo NS. The effect of epidermal growth factor on matrix metalloproteinases and tissue inhibitors of metalloproteinase gene expression in cultured human gingival fibroblasts. Archives of oral biology 2007;52:585-590.

111. Kawahara H, Kawahara D, Mimura Y, Takashima Y, Ong JL. Morphologic studies on the biologic seal of titanium implants. Report II.In vivo study on the defending mechanism of epithelial adhesion/attachment against invase factors. International Journal of Oral \& Maxillofacial Implants 1998;13:465-473.

112. Mustafa K, Lopez BS, Hultenby K, Wennerberg A, Arvidson K. Attachment and proliferation of human oral fibroblasts to titanium surfaces blasted with $\mathrm{TiO} 2$ particles - A scanning electron microscopic and histomorphometric analysis. Clinical Oral Implants Research 1998;9:195-207. 